\title{
Modeling and Simulation of Electrical Power Subsystem of Nanosatellite using MATLAB
}

\author{
${ }^{1}$ Dr. T. Murali Krishna, ${ }^{2}$ S. S. Paramahamsa, ${ }^{3}$ N. Ashwini \\ ${ }^{1,3}$ Dept. of EEE, CBIT, Hyderabad, India, RCI (DRDO), Hyderabad, India \\ Email: ${ }^{1}$ tmurali5@ gmail.com, ${ }^{2}$ nashwini.anvn.92@gmail.com
}

\section{Received: $15^{\text {th }}$ December 2017, Accepted: 20th January 2018, Published: $2^{\text {th }}$ February 2018}

\begin{abstract}
The key part of any satellite for its proper function is the design of Electrical Power System (EPS) whose function is to provide required energy during normal as well as eclipse periods. The main function of EPS is to generate power from solar energy through solar panels mounted on the satellite surface to supply power to loads during normal period and the output voltage is regulated to charge the battery which is required to deliver energy during eclipse. This paper describes the modeling, simulation of a EPS for a Nano satellite in MATLAB Simulink environment.
\end{abstract}

Keywords: Solar cells, Direct energy transfer Batteries, Buck converter, Ćuk converter

\section{Introduction}

Nano satellites are typically defined as artificial satellites with a mass between 2.2 and $22.0 \mathrm{lbs}$. Advances in technology have allowed for lower costs in manufacturing, miniaturization of components, and increased overall utility of technology [1]. Nano satellite has a scientific payload attitude control system, communication system etc, with unique power requirements, therefore there is a need to design and develop a relatively low cost system to suit the operation requirements.

The Nano satellite considered for this simulation is a cuboid shaped and weighs approximately $4 \mathrm{kgs}$ which has body mounted solar panels on three sides of its six sides which are going to be deployed in the space. The other three sides are neglected because they will never face the sun or gets any illumination [2]. One of its sides i.e. the nadir side contains the payload which is the objective of the Nano satellite.

Solar energy is the only source of energy in space and the operation of the entire satellite depends on this energy. The role of EPS is to generate, condition and distribute the electrical power to the satellite loads for their functioning [3]. The EPS consists of solar panels which are connected in combination of series and parallel strings for generation. For storage, Li-ion batteries are connected to the bus which is charged during sunlit period and the energy stored is used during the eclipses [4]. For this, power budgeting is to be done so that electronic converters are to be modelled to cater the required energy to various sections of the satellite [5].
The design process of any satellite sub-system strongly depends on orbital parameters such as the type of orbit, orbital height, inclination, time spent in the sun, time spent in eclipse, average orbits per day and average orbits for the extent of the mission etc. From these calculations, the key aspects which influence the size of the battery like number of charging, discharging cycles and depth of the discharge will be determined [6].

\section{Modeling of Electrical Power System}

The functions of the power subsystem is to

a) supply continuous electrical power to the satellite during its entire mission life,

b) control and distribute power to the spacecraft and

c) support power requirements for peak and average electrical load and protect the spacecraft payload operations against failures within the electrical power subsystem.

Nano satellite would have an estimated mission life of 2 years with an orbit average/peak power of 36 $\mathrm{W}$. It should provide a nominal output voltage of $15 \mathrm{~V}$ when placed at $650-800 \mathrm{~km}$ altitude, Low Earth Orbit (LEO).

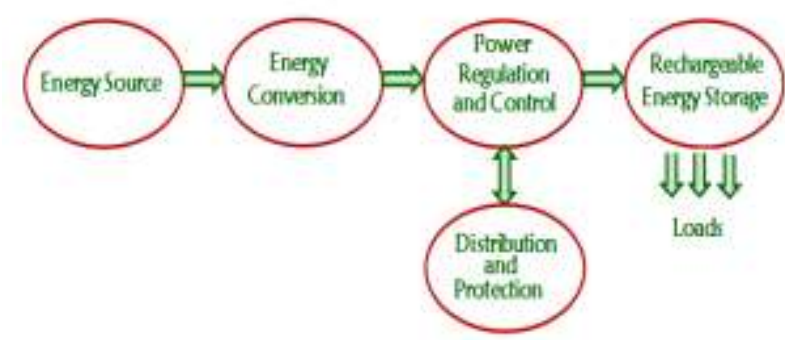

Fig. 1: Nano satellite Power System Architecture

The information regarding orbital parameters like altitude, eccentricity, inclination, local time, the resulting durations of sunlit and eclipse phases per orbit are essential in the design of EPS. In addition to this, quality of the distributed power, such as power bus service voltage range, power bus stability at load change, source impedance and interference voltages are also required.

\section{PoWer BUdGeT}

The estimation of the power required by the payload and different subsystems is termed as power budget which gives an idea of how much power is required by the satellite in different operating modes during 
its lifetime. Apart from defining the required power production capability, the power budget also helps develop schemes for special operating modes like load shedding, duty cycling, etc. Hence power system shall provide enough power to meet both eclipse and peak power requirements defined by the power budget. These calculations will then be balanced to ensure that there is sufficient energy for Nano satellite to complete its mission. Power consumption is first estimated based on assuming the loads to be active during a specific function.

\section{TABLE I}

\begin{tabular}{|c|c|c|c|c|c|}
\hline \multirow[b]{2}{*}{ S.No } & \multicolumn{5}{|c|}{ Power Budget } \\
\hline & Subsystem & $\begin{array}{l}\text { Operating } \\
\text { voltage }(V)\end{array}$ & $\begin{array}{c}\text { Load } \\
\text { current }(\mathrm{A} \\
)\end{array}$ & $\begin{array}{r}\text { Required } \\
\text { Power(W) }\end{array}$ & $\begin{array}{c}\text { Time } \\
\text { of } \\
\text { usage }\end{array}$ \\
\hline 1 & $\begin{array}{l}\text { RF } \\
\text { transmitter }\end{array}$ & 5 & 0.34 & 1.7 & $\begin{array}{l}\text { All } \\
\text { times }\end{array}$ \\
\hline 2 & $\begin{array}{l}\text { Magnetic } \\
\text { Torquer }\end{array}$ & 5 & 0.3 & 1.5 & $\begin{array}{l}\text { All } \\
\text { times }\end{array}$ \\
\hline $\mathbf{3}$ & OBC & 3.3 & 0.45 & 1.5 & $\begin{array}{l}\text { All } \\
\text { times }\end{array}$ \\
\hline 4 & IMU+GPS & 5 & 0.25 & 1.25 & $\begin{array}{l}\text { All } \\
\text { times }\end{array}$ \\
\hline 5 & $\mathrm{RF}$ receiver & 5 & 0.48 & 2.4 & $\begin{array}{l}\text { All } \\
\text { times }\end{array}$ \\
\hline 6 & Heaters & 5 & 0.36 & 1.8 & $\begin{array}{l}\text { All } \\
\text { times }\end{array}$ \\
\hline 7 & $\begin{array}{l}\text { Reaction } \\
\text { wheel }\end{array}$ & 5 & 0.2 & 1 & $\begin{array}{l}\text { All } \\
\text { times }\end{array}$ \\
\hline \multicolumn{6}{|c|}{ Total Housekeeping power $=\mathbf{1 1 . 1 5 W}$} \\
\hline 8 & $\begin{array}{l}\mathrm{x} \text {-band data } \\
\text { transmitter }\end{array}$ & 5 & 0.8 & 4 & $\begin{array}{l}10 \mathrm{mi} \\
\mathrm{n}\end{array}$ \\
\hline 9 & $\begin{array}{l}\text { Payload } \\
\text { power }\end{array}$ & 5 & 1 & 5 & $\begin{array}{l}10 \\
\min \end{array}$ \\
\hline 10 & Battery & 4.2 & 5.285 & 22.2 & \\
\hline \multicolumn{6}{|c|}{ Payload and transmission power $=\mathbf{9 W}$} \\
\hline \multicolumn{6}{|c|}{ Total LOAD POWER $=32.44 \mathrm{~W}$} \\
\hline
\end{tabular}

As the bus is battery tied bus, the battery is designed first so that the voltage is clamped at battery. The power the battery has to support during the eclipse is found out by the eclipse housekeeping power, The eclipse payload power The energy supported by the battery during eclipse, The average battery voltage, The battery efficiency, the depth of discharge of battery, battery removed per orbit, battery capacity required etc.
TABLE II

\begin{tabular}{|c|c|}
\hline \multicolumn{2}{|l|}{ Energy balance } \\
\hline & $\begin{array}{c}\text { Energy } \\
(W h)\end{array}$ \\
\hline Battery Stored energy(a) & 7.00 \\
\hline $\begin{array}{l}\text { Energy dissipated by the Nano } \\
\text { satellite(b) }\end{array}$ & 32.447 \\
\hline $\begin{array}{l}\text { Energy generated by the solar } \\
\operatorname{array}(\mathrm{c})\end{array}$ & 45.264 \\
\hline Energy Balance $(a+c-b)$ & 19.817 \\
\hline
\end{tabular}

As the energy balance is positive, it can be observed that the power consumption is less than the power generation and its storage. Hence the Nano satellite EPS design is reliable and the Nano satellite will not have power requirement issues during its operation period.

According to the minimum power requirement and battery requirements solar array has to be designed. Total number of solar cells taken is 54 . Number of cell taken on each panel of Nano satellite is 18 , Voltage of each cell is $2.1 \mathrm{~V}$. The average bus voltage is $14.8 \mathrm{~V}$ as calculated from battery sizing.

\section{Simulation}

The solar array is modeled according to the requirement of the Nano satellite. Total number of cells required is 54 in which 9 cells are connected in series in a string. The number of strings per panel is 2 and the number of panels is 3 . The equations required to produce the desired output are simulated in Simulink blocks as shown in figure2. The corresponding voltage, current and power waveforms of solar array are represented in the figures 3, 4 and 5 respectively.

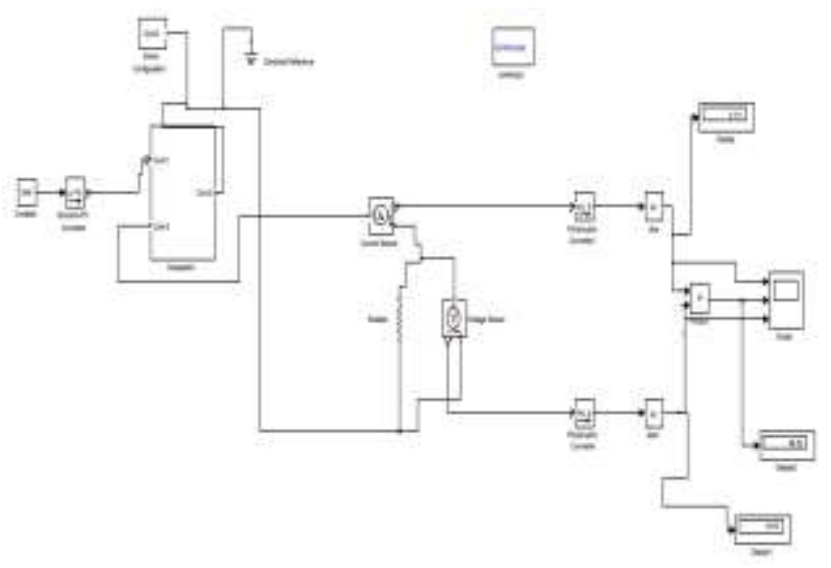

Fig.2: Simulation model of solar array 


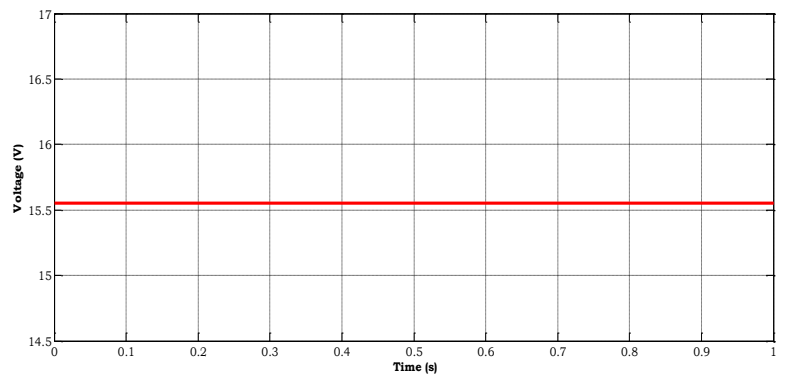

Fig. 3: Output voltage waveforms of solar array

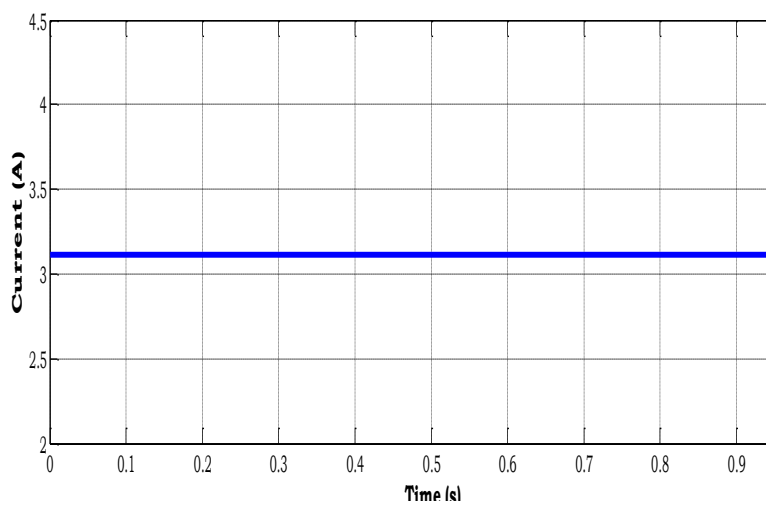

Fig.4: Outputcurrent waveforms of solar array

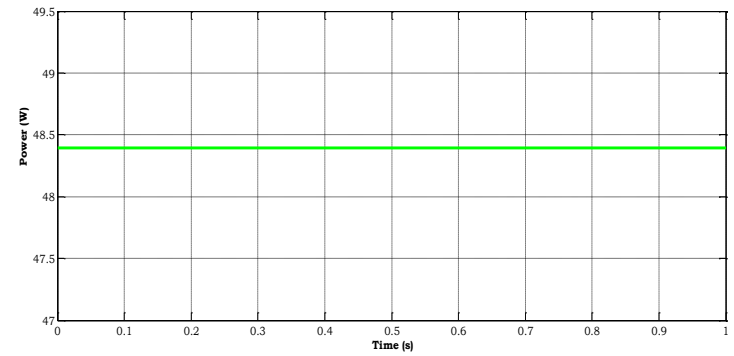

Fig.5. Output power waveforms of solar array

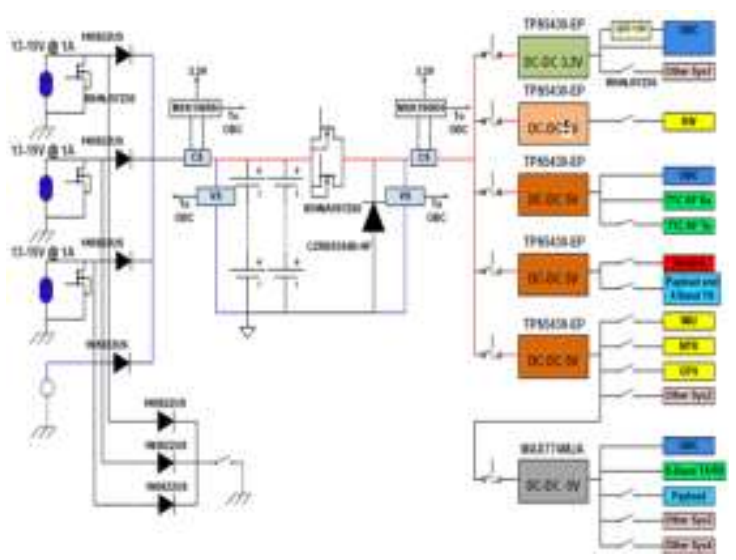

Fig.6: Nano satellite Power System Block schematics

The block diagram of the EPS required for the satellite considered is represented by the figure 6 . The output of the solar panels is required to be controlled. The obtained dc output must be converted into different dc voltages using suitable dc-dc converters. The bus voltage is $15.5 \mathrm{~V}$; the nominal voltage of the battery is $4.1 \mathrm{~V}$. Hence, to charge the battery a buck converter is required. The simulation model of battery charger is shown in figure 7 and its state of charge is shown in figure 8 .

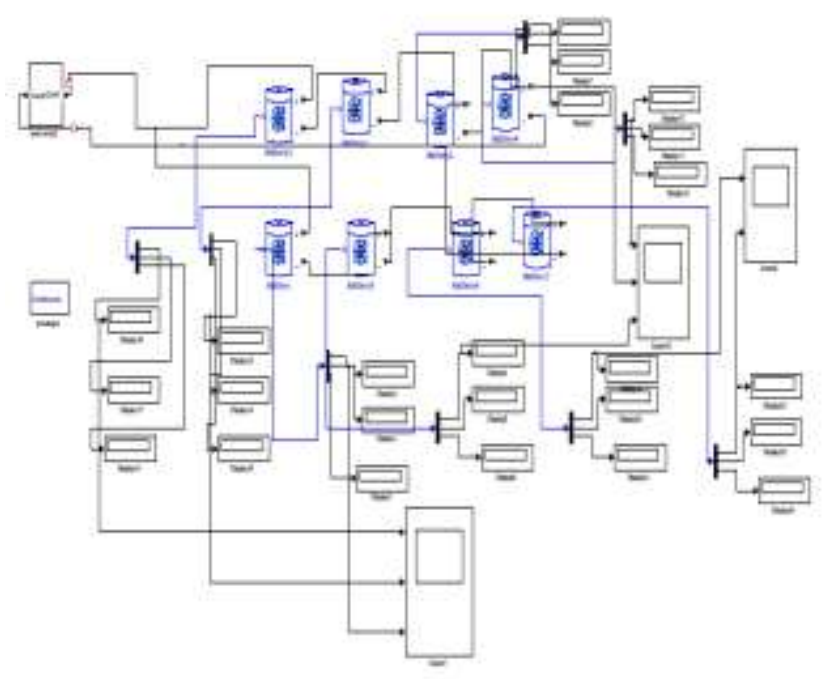

Fig.7.Battery charging simulation model

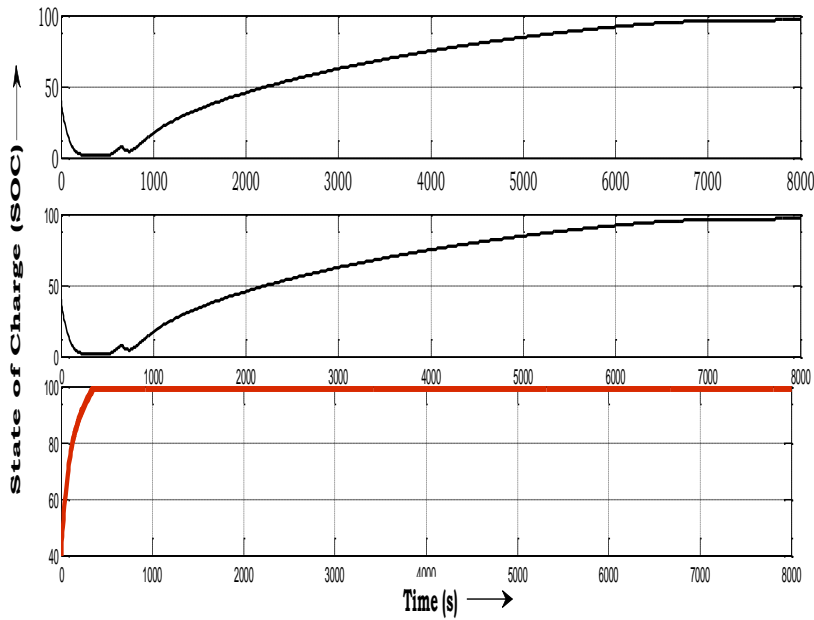

Fig.8. State of charge of batteries

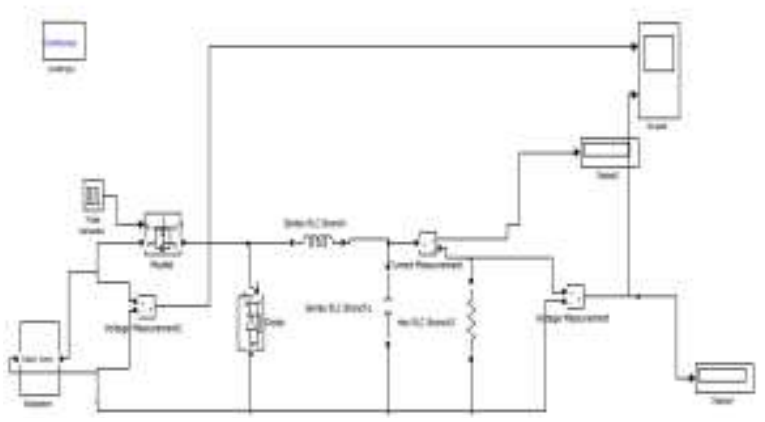

Fig.9.Simulated model of buck converter 
From the battery voltage bus, the voltage is required to be stepped down to run the subsystems of the Nano satellite. Hence, a buck converter is used. According to the required output voltage the dc-dc converter has been designed and the dc-dc converter is modeled for simulation in MATLAB.

\section{Results and Discussion}
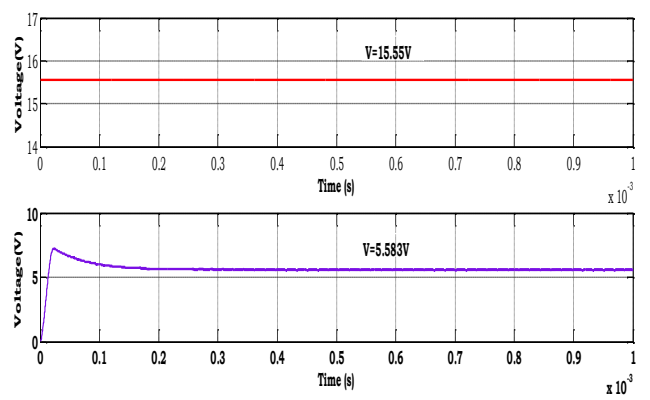

Fig.10. Output waveforms of buck converter of output 5 V

The simulation model of buck converter for an output voltage $5 \mathrm{~V}$ when the input voltage is $15.55 \mathrm{~V}$ is given in the figure 9 . The input and output voltage waveforms are shown in figure 10. The loads here considered are resistive loads.
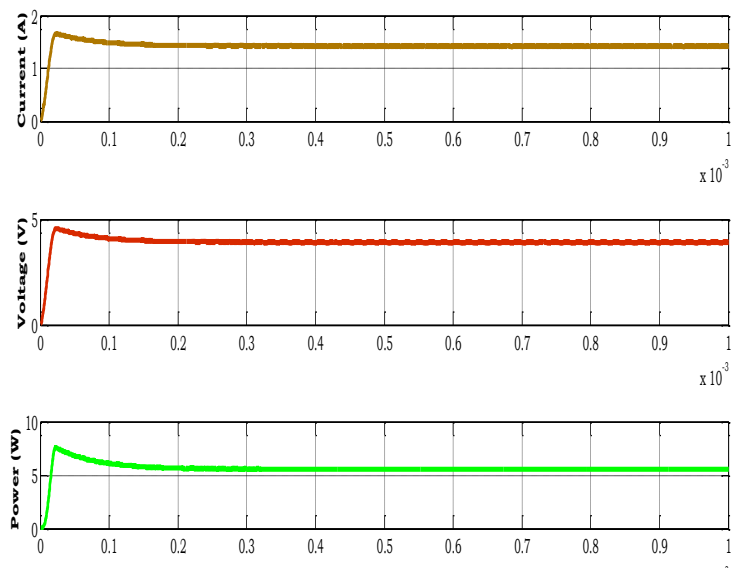

Fig 11: Output current, voltage and power waveforms of load

The load connected to the buck converter of output $5 \mathrm{~V}$ is $2.75 \Omega$. Current drawn by the load is $1.417 \mathrm{~A}$ and voltage is $3.897 \mathrm{~V}$ hence power consumed is 5.52204W.
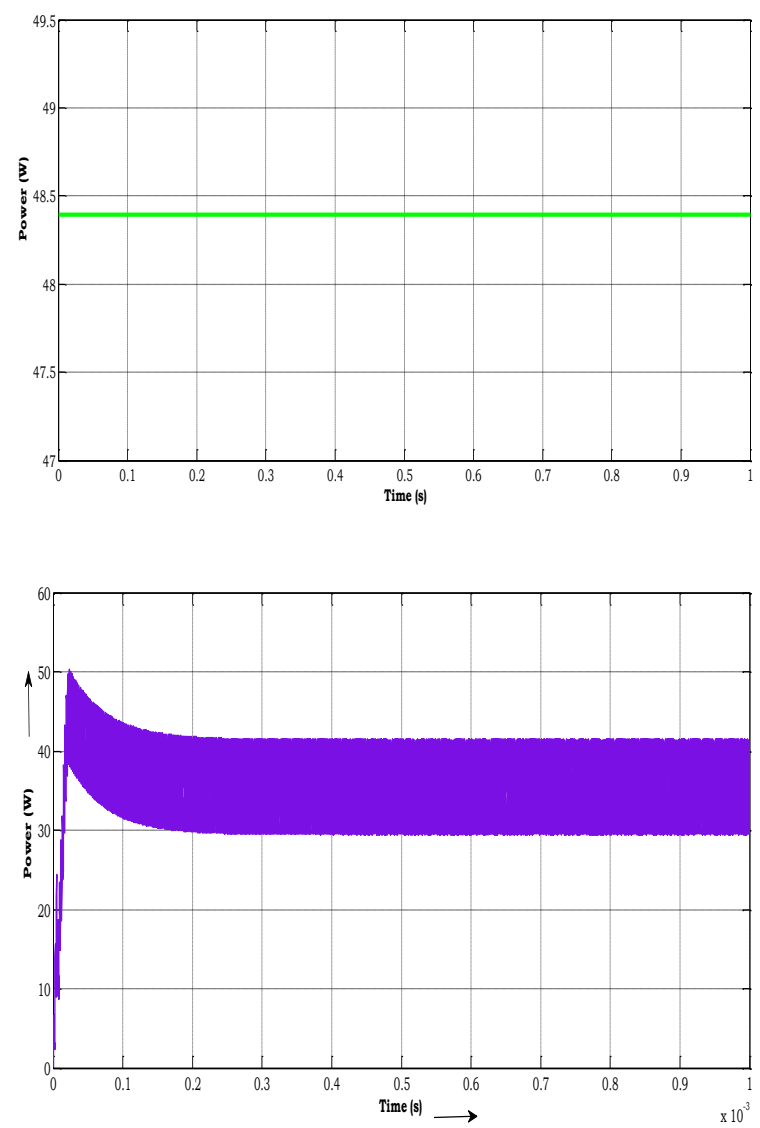

Fig 12: Output waveforms of EPS

The power consumed is shown in the figure 12 . Power generated is $48.205 \mathrm{~W}$ and the total power consumed is $29.32 \mathrm{~W}$. As the power generated is more than the power consumed, the Nano satellite EPS design is reliable and can supply enough power to other subsystems of Nano satellite without failing during its period of operation.

\section{Conclusion}

In this paper, a Nano satellite EPS is simulated and its output voltages are observed. The major role of this work is to model the EPS in the face of continuously changing power requirements. This means that the EPS could be potentially overdesigned if unnecessary parameters are included. The EPS components like solar panels, batteries and DC-DC converter are designed and simulated in MATLAB. The results obtained show that the power consumed by the loads is less than the power generated by the solar panels hence the Nano satellite EPS system is reliable. 


\section{References}

1. Mukund R. Patel, "SPACECRAFT POWER SYSTEMS" by CRC PRESS Boca Raton London New York Washington, D.C.

2. Anil K. Maini, Varsha Agrawal "satellite Technology Principles and

Applications"Defence research and development organization, ministry of defence, India.

3. Wilfried Ley, Klaus Wittmann and Willi Hallmann "Handbook of Space Technology" (C) 2009 John Wiley \& Sons, Ltd. ISBN: 978-0-470-697399

4. Ibraham Tahir, "Design and implementation of EPS of a cubesat", University of Khartoum, Sept. 2012.

5. Ned Mohan, Tore M Undeland, William P. Robbins, "Power Electronics-Converter, Applications and Design” By John Wiley \&Sons. Inc.

6. Christopher J. Ortiona, "Systems Level Engineering of Advanced Experimental Nanosatellites," Naval Postgraduate School, Monterey, Master's Thesis 2009. 